\title{
Organizational and economic changes in the development of enterprise architecture
}

\author{
Aleksei Anisiforov ${ }^{1}$, Alissa Dubgorn ${ }^{1, *}$, and Aleksandr Lepekhin ${ }^{1}$ \\ ${ }^{1}$ Peter the Great St.Petersburg Polytechnic University, Polytechnicheskaya, 29, St. Petersburg, \\ 195251, Russia
}

\begin{abstract}
The paper describes the synchronization of strategic and operational tasks of business with the development and ongoing operation of information systems of the enterprise. The issue of developing information systems architecture in a constantly changing landscape of business processes is investigated in the context of enterprise architectural approach.
\end{abstract}

\section{Introduction}

Information resources play a key role in the development of a business, the growth of its innovative potential and the increase in the efficiency of its activities. The quality of the information support of an enterprise depends on the implementation of its corporate strategy, competitiveness and financial viability. The possibility of increasing the efficiency of using information resources in an enterprise is subject to the creation of a single information space and the creation of an IT infrastructure based on modern methods and models for building information systems, systems for exchanging data, knowledge and relevant information technologies. The construction and development of the information infrastructure becomes possible only on the basis of a modern architectural approach that provides a certain balance between the information needs of a business in solving management tasks and the possibilities of information support for these needs, i.e. an enterprise architecture (EA) model needs to be developed. The key issue in EA is the alignment of information systems architecture with the business architecture. The architectural model of enterprise management allows you to convert the strategic goals of enterprise development and the objectives of its operational activities into a business architecture and ensures its implementation by resources of the system architecture, the core of which is the architecture of information systems [1]. Methods, approaches and tools that ensure the coordination of business development strategies and the development of information systems architecture in the EA represent the subject of this research work.

\footnotetext{
*Corresponding author: alyovina@gmail.com
} 


\section{Architectural approach to information resources management}

\subsection{Elements of enterprise architecture and their relationship}

The management of any enterprise is a set of complex processes covering interrelated subject areas - from pre-production and procurement to product sales and interaction with customers. Within each process, there is a transformation of any resources (material, labor, financial, production, etc.). To make a management decision, each process must have an informational reflection. Thus, in management there are always two streams, the first is the resource flow, and the second is the informational reflection of this flow, which makes it possible to make a decision on the state of the resource and, if necessary, to change this state. Obviously, the effectiveness of the decisions made by the management depends on the quality of the information used.

EA is a concept that allows you to build organizational, economic and information technology components, on which the business processes are based, thus creating an integrated information environment for making management decisions. It provides rapid transformation of architectural solutions in case of any changes in the organizational and economic, as well as in IT fields. It also offers a range of modern methods, models, tools and technologies that allow the integration, accumulation and use of data and knowledge about management processes and ensure their availability with the use of technical tools and application solutions [2].

Thus, the EA is the most important tool for the accumulation and use of knowledge, as well as a systematic description of the activities of the enterprise. It is used to analyze the existing and design the future state of the enterprise, as well as to present alternative scenarios for its development and achieving its strategic goals.

A number of methodologies, models, and frameworks are used to describe and develop EA, such as [3]:

- The Zachman Framework for Enterprise Architecture model, first introduced as an information systems architecture model, and then extended to the entire enterprise;

- TOGAF (The Open Group Architecture Framework) methodology, including, in particular, the ADM (Architecture Development Method);

- FEA (Federal Enterprise Architecture) methodology - a framework developed for building architectures of US government organizations;

- Gartner model and others.

Most of the methods offer the following domains to be distinguished in EA: businessarchitecture, information (data) architecture, application architecture, and technology architecture. The last three domains together form the system architecture and are rigidly logically related. In addition to the specified domains, in the description of the enterprise architecture, such specialized areas as security, service support, IT personnel management, etc. are distinguished. In their unity, they constitute the architecture of information systems.

\subsection{The key role of business architecture in the creation and development of architectural solutions}

The architectural management model allows you to use the methods and tools of the company management to support strategic and operational management, synchronizing the management and development processes of IT and business. In the course of its development, the concept of accreditation management pays more and more attention to business models, organizational structure accumulated in knowledge management, a number of important business concepts and their influence on IT architecture, i.e. the role of the business 
architecture increases significantly, and the business requirements for the information systems architecture and other elements of the EA are increasing.

Thus, the EA, being an effective tool for the systemic description of the enterprise's activities, allows the integration of data and knowledge about management processes and their availability for decision-making by management. And here the technical platform and system architecture corresponding to the management model are of great importance. Determining the requirements of a business model and analyzing their changes allows us to develop an architecture of information systems. These requirements are also formed by other components of the architecture (hardware, network protocols, related application solutions, etc.). The architecture of information systems includes not only data on the organization of information systems, its structural elements and interfaces, but also focuses on usability, flexibility, limitations, risks during creation and operation, as well as the organization of interaction with other elements of the system architecture [4].

The evolution of the architecture of information systems begins in the early stages of the life cycle, and in the process of operation, new elements emerge as a reaction to changes in the economic environment and IT infrastructure. The architectural management model allows you to make the architecture of information systems robust to change, providing the desired purpose and functionality. The basis for creating an information system architecture is a business architecture that is presented in the form of a business model that includes a business process system that defines the duties and competencies that co-workers involved in these processes should have. It is the business model that is the basis for the formation of requirements for the information systems architecture, and then for the information system itself. It is also the basis for the formulation of requirements for changes and allows you to perform a chain of necessary changes not only in the architecture of information systems, but also in the system architecture. To describe a business process model, various modeling notation is used, for example, VAD, EPC, "Procedure", as well as IDEF notation. The language UML is widely used to formalize requirements to the information system and build an information systems architecture. UML diagrams allow you to define objects, events, and domain elements, but the difficulty lies in the fact that such a model is not focused on the processes with which the business works.

It should be recalled that the architectural management model assumes a process approach to building a management system that has proven its effectiveness in projects of the EA models' development. However, with the implementation of such projects, the complexity of engineering activities at the enterprise became obvious. The built business model must be maintained, current changes must be made in it, it must be executed and service support should be provided. The rapid development of economic processes in the global economy and at the enterprise itself often makes it necessary to correct the process structure of the business model, which cannot be maintained without a quick and adequate response to changes in the system architecture. It is also difficult to implement innovations that ensure the growth of the innovative potential of the enterprise, investment projects aimed at modernizing the business, the release of new products, the development of new markets, etc. The formed portfolios of innovation and investment projects require serious architectural support, since their execution relies on information and other resources of the enterprise [5].

The development of architecture in accordance with the requirements of the business forces to use the basic technologies (methodologies) of designing information system, in particular, RUP, MSF, Oracle CDM and others. They allow you to implement a project of changes affecting all levels of EA [6]. In the event of a fundamental change in the structure of the business and its strategy, a portfolio of information system architecture development projects can be formed, which should be managed with minimal risks for the EA.

Thus, the business architecture forms the entire system of requirements for the remaining elements of the enterprise's architecture, and its creation and development rely on a number 
of concepts, among which the most important is the architectural approach that ensures the coordination of strategies and operational plans for business development and IT, which allows requirements for infrastructure changes, monitors the execution of budgets and ensures the current documentation of the EA.

\subsection{Information systems architecture as a basic element of enterprise system architecture}

The system architecture, which is supporting business architecture includes the information architecture, the architecture of applications, the system-technical architecture, which creates a platform for the functioning of applications and work with information. In addition, there are additional domains - providing integration, communication, security [7], customer service, and IT operation. But the basic element of the system architecture is the architecture of information systems, which consists of information architecture and application architecture. The information architecture determines what data is necessary to support business processes, allows you to create a model of data, provides the possibility of its accumulation, development and use of applied solutions. The application architecture determines the composition of the application systems that an enterprise needs to perform business processes and includes such issues as design, development, integration, and operation of application systems, determines which applications should be used for data management and support of business functions [8]. It is impossible to consider these domains separately, speaking about the synchronization of business and IT development, since the architecture is the core of the architectural management model that ensures the realization of the information balance in the enterprise management system mentioned above.

The development strategy of the information systems architecture is aimed at achieving and strengthening the organization's necessary competences in the field of IT, designed to strengthen the company's position in the market and ensuring the implementation of the business strategy [9]. It supports the business strategy, ensuring the achievement of the strategic goals and mission of the company. As quite rightly noted in [10] "an important feature of an IT strategy as a functional strategy is that, in addition to supporting a business strategy, it must be aligned with other functional strategies (for example, financial strategy, marketing strategy, etc.)". It should not be forgotten that developmental processes do not cancel the operation of information system, i.e. IT resources should be available to the user in specified conditions and modes.

For the first time, an architectural approach to business alignment and IT was proposed in the work of M. Parker [11], where it was argued that planning the architecture of an information system is a strategically important task, as it helps to achieve a high level of compliance of information system capabilities with business needs.

The fundamentals of the architectural approach to the management of information systems architecture and administration in general were laid by well-known works by J. Zachman, and the generalized scheme (framework) of the enterprise architecture for Zahman became the de facto standard [12]. Despite the large number of methods of creating EA, many organizations are limited in practice when describing activities in the following subject areas: goals, organizational structure, key performance indicators, business processes, documents, information systems, personnel knowledge and powers. The business architecture is created on the basis of process management, and for its development, business performance management systems (BPM) are used. The BPM system monitors business processes, accumulates valuable statistics on their performance parameters and provides a basic set of reports on business process indicators. On their basis, key performance indicators (KPI) can be set, which, in turn, can be linked to the Balanced Scorecard (BSC). 


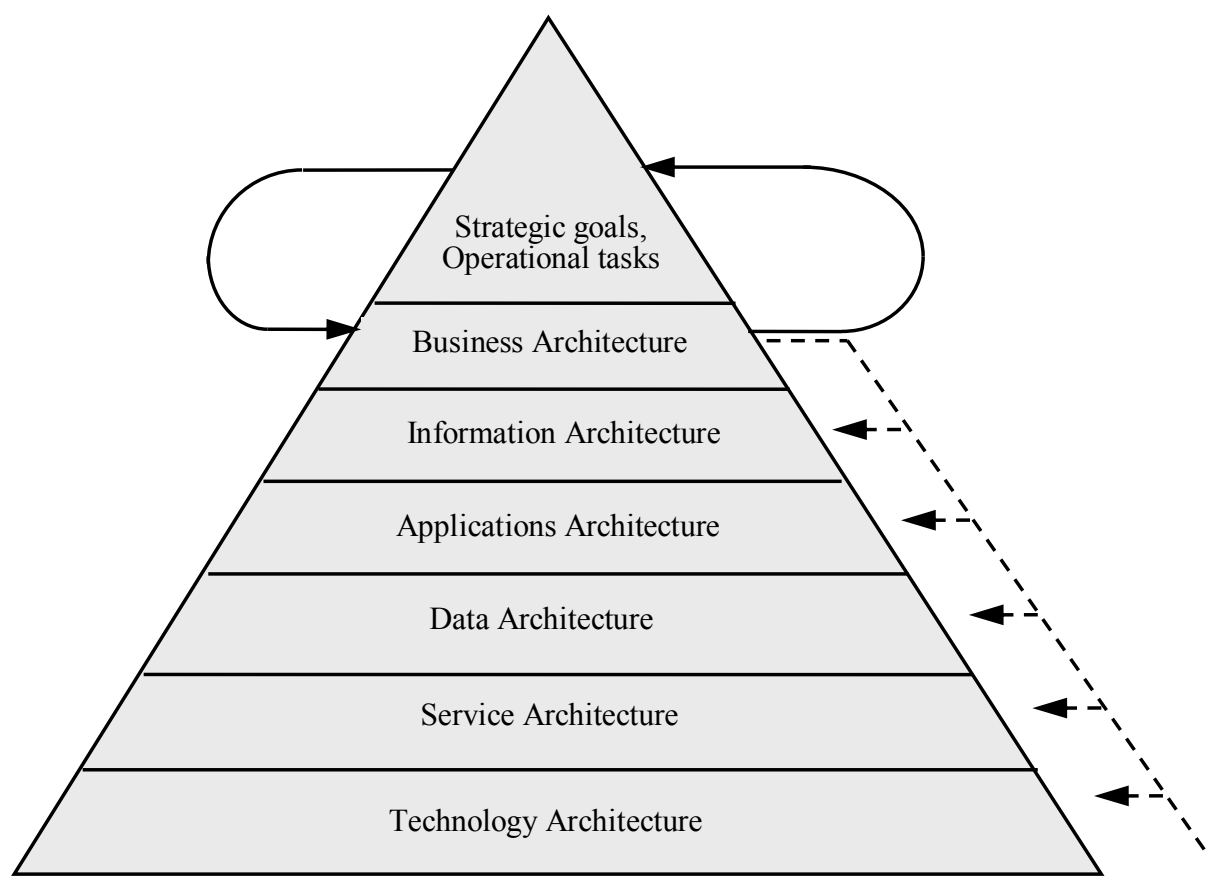

Fig. 1. Enterprise Architecture domains.

The system of business processes and the requirements for its information support form the requirements for the creation and development of information systems architecture. Changing the landscape of business processes in the course of continuous business development requires improving the management of business processes as a whole due to the mutual adaptation of the information systems architecture, IT services and the structure and content of business processes.

The adaptation of the architecture of information systems to changes in the needs of the management system must be continuous and implies changes in the architecture of information systems at the operational, tactical and strategic levels. This requires improvement and synchronization of information flows supporting business processes, improvement of the quality of methods, models and knowledge systems accumulated in the EA when making management decisions and the continuous development of business architecture.

It should also be noted that the integration and accumulation of information in the EA allow you to form a knowledge system, as "a set of accumulated experience, values, contextual information and expert assessments that are possessed" by specialists of the enterprise management system. This knowledge is used both to make management decisions and to carry out organizational changes in the enterprise, allowing you to link various development initiatives, translate strategy into actions, and ensure the coherence of the various elements of the enterprise. There is a need for continuous improvement of the IT infrastructure and business model. And this requires constant monitoring of the status of all domains of the EA. 


\section{Problems of managing the architecture of enterprise information systems in the process of its development}

\subsection{Basics of information monitoring in the enterprise and its role in the development of information systems architecture}

The development of a strategy for creating and developing an architecture of information systems in accordance with a business development strategy is always associated with an analysis of the current state of an enterprise management system, including the information infrastructure of an enterprise, i.e. EA monitoring. Analysis of the organizational, economic and information processes of an enterprise requires an assessment of the parameters of all its activities, an assessment of the possible impact of external factors, the need for forecasting for making management decisions, and raises the question of effective information support for enterprise management processes. For the analysis of information processes, it is necessary to have a system of models that allows you to control the entire information space of an enterprise. The quality of such a system is played by the administration itself, which allows you to create an integrated information base that describes the business structure, a system of information necessary to support business management processes and enterprise development processes, and the architectural management model provides the possibility of designing an information system adequate in terms of meeting the needs of the organization, and capable of interaction, integration and development. The development of EA in accordance with the requirements of external and internal economic environment and IT requires constant monitoring of its condition [13]. In the process of monitoring the EA, the parameters, indicators, observations, criteria, etc., are monitored to assess its condition.

Each of these two domains requires unique methods and tools for monitoring. Certain possibilities for the monitoring process are provided by the audit of the architecture, in accordance with, for example, the COBIT standard. This standard defines the approaches and principles of IT management in the enterprise, focusing on the strict compliance of IT resources and IT processes with the business needs of the enterprise. To control the quality and consistency of IT processes, monitoring and auditing processes included in the conceptual core of the standard should be carried out on a regular basis. Thus, the COBIT standard not only allows building the architecture of information systems based on business requirements and the conditions of austerity of resources, but also gives clear recommendations on the efficient use of these resources. However, in any case, a single monitoring information system should be formed for the entire IT infrastructure of the enterprise. This is due to the need to address during the monitoring of a number of organizational and technical problems, such as: evaluation of the efficiency of the IP; evaluation of user interaction convenience; evaluation of application servers and database servers; identifying problem areas that impede the stable operation of information systems. The monitoring system allows you to develop recommendations and requirements for adjusting the architecture of information systems, to respond quickly to incidents and problems in the IT infrastructure and to ensure the restoration of the functioning of information systems.

Description of the architecture of information systems in the form of a set of models (use cases, deployment, design and implementation) in accordance with the RUP methodology allows monitoring the compliance of the business model and information systems architecture. This methodology allows you to build a model of the formation of the architecture of the information system and its use in the form of UML diagrams. The analysis of the compliance of the business model and the architecture model of the information system can be performed using an analytical model, the construction of which provides control over the fulfillment of requirements for the information system and its internal organization when 
changes are made. Such a model can be called an architectural model of business development. The quality of the description of the business model at all stages of its development plays a huge role in monitoring the compliance of the business architecture and IT infrastructure. To build this model, a lot of business engineering tools are used. The choice of a specific tool is determined in accordance with the decision of specialists to create and maintain the system of business processes of the organization. The business model should give a clear idea of what support is required for each user of the information system. Analysis of this business model makes it possible to identify the fulfillment of direct requirements. But there are additional requirements - performance, availability, security, restrictions, time, interfaces, etc., the implementation of which should be monitored during the monitoring of the system architecture. Therefore, the monitoring processes of information systems architecture should be considered as a whole in the complex of the monitoring system of the EA as a whole.

\subsection{Methods of creation and development of information systems architecture}

The development of an information systems architecture development strategy should be based on a complete and comprehensive knowledge of the state of the enterprise's information infrastructure, the state of business architecture and a clear description of the business development strategy. The formation of an information systems development strategy should be carried out taking into account the existing constraints (financial, temporary, technical, etc.) and an adequate assessment of the level of corporate culture existing in the enterprise. Almost all of this knowledge can be obtained as a result of continuous monitoring of the EA, which was discussed above.

Strategy development always assumes the existence of goals and the identification of ways to achieve them, getting answers to key questions - what to do, why and how to do this. Answers to these questions can be obtained only with the joint work of representatives of business and IT services. The constant change in business needs, difficulties with the description of information flows and the coordination of business and IT interaction, mutual misunderstanding of the proposed ways to achieve the goal leads to a number of contradictions that have to be overcome in the formation of the EA and the development strategy of information systems. The developed strategy should make the process of achieving the goal manageable and understandable to all participants, that is, should determine its implementation plan and the responsibilities of the participants.

The formation of the strategy for the development of information systems architecture must necessarily be related to the plans for the development of the IT infrastructure and the provision of the necessary level of IT services associated with new business processes and the integration of applications supporting them. Thus, the development of a strategy for the development of the architecture of information systems affects not only the processes of managing applications and data in the new state of the architecture, but also the problems of operating the entire IT infrastructure. Consequently, its development requires universal methods and tools, the use of which will allow to solve this problem. First of all, these are architectural frameworks, for example, the previously mentioned Zachman model and the TOGAF methodology. These are methodologies for designing information systems, including: RUP (Rational Unified Process) - a deeply developed methodology for iterative development of information systems and software solutions; MSF (Microsoft Solutions Framework) - a package of guidelines for effective design, development and the implementation of IT solutions, which is the result of the generalization of Microsoft's knowledge and experience in the development of business applications. These are the best IT support practices based on the service process approach [14]. The most famous and widely used in practice are the recommendations of ITIL (Information Technology Infrastructure 
Library). The set of processes described in ITIL books is used to implement the concept of ITSM, i.e. IT service management approach that addresses business needs by using a rational combination of people, processes and information technology. The ITIL / ITSM model is open and the most popular. However, there are other approaches, for example, MOF methodology (Microsoft Operations Framework), which is a library of documents based on ITIL ideas and summarizing the experience of maintenance and support of IT infrastructure accumulated by Microsoft consulting service based on the analysis of implemented projects and taking into account the specifics of using Microsoft solutions in building a technological architecture. Equally important for solving the problem in question are the methods and tools for building a business architecture, since it is this that is the basis for formulating comprehensive requirements for the development of information systems architecture.

The development of the ICT market offers to the businesses some increasingly sophisticated solutions, technologies, analytical capabilities, tools, and hardware that may not yet be in demand by a particular enterprise. However, the use of their opportunities can provide competitive advantages, change the company's position in the market and provide businesses with greater opportunities. Thus, when developing an information systems architecture development strategy, one should rely not only on current and even future information needs, but also take into account new and prospective ICT capabilities. In addition, as a result of EA monitoring and IT auditing, significant deficiencies in the technological architecture that hinder the development of the information systems architecture can be identified. The risk of such a problem should be taken into account when developing a strategy for the creation and development of information systems architecture.

\section{Conclusion}

Thus, the presented work studied the problem of managing information resources of an enterprise based on an architectural model of business management. The construction of such a model allows you to convert the constantly changing information needs of business to the creation of an adequate information infrastructure of an enterprise, which creates the opportunity to build an architectural model of business development. A key element of this model is the information system architecture, which interacts with resources on the basis of a technical platform and supports management processes. The architectural model of business development, based on modern methods and models of building information systems, systems for exchanging data, knowledge, and information technologies, is becoming an essential tool for synchronizing business development strategies and information systems architecture. The construction of such a model becomes possible under the condition of continuous monitoring of the EA and audit of the information infrastructure.

\section{References}

1. I. Ilin, A. Anisiforov, Proceedings of the 2014 International Conference on Economics and Applied Statistics (EAS '14). Recent Advances in Mathematical Methods in Applied Sciences Sciences (MMAS '14), 432-437 (2014)

2. I. Ilin, A. Levina, O. Iliashenko, MATEC Web of Conferences, International Science Conference SPbWOSCE-2016 "SMART City" 106 (2017)

3. M. Lankhorst, Enterprise Architecture at Work: Modelling, Communication and Analysis (Springer, Heidelberg, 2013)

4. J. Zachman, IBM Systems Journal 3(26), 276-292 (1987) 
5. I. Ilin, A. Anisiforov, WSEAS Transactions on Business and Economics 11, 757-764 (2014)

6. A. Jacobson, G. Buch, J. Rambo, Unified process of software development (Piter, SaintPetersburg, 2002)

7. V.V. Glukhov, I.V. Ilin, A.B. Anisiforov, Proceedings of the 8th International Conference on Security of Information and Networks, 34-37 (2015)

8. A. Danilin, A. Slyusarenko, Architecure and strategy - yin and yang of enterprise information technology (Intuit, Moscow, 2005)

9. A.D. Borremans, I.M. Zaychenko, O.Yu. Iliashenko, MATEC Web of Conferences, International Science Conference on Business Technologies for Sustainable Urban Development 170, 010342017 (2018)

10. I. Leshakov, Young Scientist 21, 13-16 (2017)

11. M. Parker, R. Benson, Journal of Information Systems Management 3(6), 14-23 (1989)

12. J. Sowa, J. Zachman, IBM System Journal 3(31) (1992)

13. A.B. Anisiforov, A.S. Dubgorn, Proceedings of the 29th International Business Information Management Association Conference - Education Excellence and Innovation Management through Vision 2020: From Regional Development Sustainability to Global Economic Growth, 2920-2930 (2017)

14. T. DuMoulin, R. Flores, B. Fine, Defining IT Success Through The Service Catalog: A Practical Guide. $2^{\text {nd }}$ edition (Pink Elephant, 2008) 